\title{
Portal vein ligation alters coding and non-coding gene expression in rat livers
}

\begin{tabular}{|c|c|}
\hline Journal: & Biochemistry and Cell Biology \\
\hline Manuscript ID & bcb-2017-0070.R2 \\
\hline Manuscript Type: & Article \\
\hline Date Submitted by the Author: & 17-Aug-2017 \\
\hline Complete List of Authors: & $\begin{array}{l}\text { Li, Bin; Second Military Medical University, Eastern Hepatobiliary Surgery } \\
\text { Hospital } \\
\text { Zhu, Yan; Second Military Medical University, Changhai hospital } \\
\text { Xie, Lei; Second Military Medical University, Eastern Hepatobiliary Surgery } \\
\text { Hospital } \\
\text { Hu, Shuyang; Second Military Medical University, Eastern Hepatobiliary } \\
\text { Surgery Hospital } \\
\text { Liu, Shupeng; Second Military Medical University, Changhai hospital } \\
\text { Jiang, Xiaoqing; Second Military Medical University, Eastern Hepatobiliary } \\
\text { Surgery Hospital }\end{array}$ \\
\hline $\begin{array}{r}\text { Is the invited manuscript for } \\
\text { consideration in a Special } \\
\text { Issue? : }\end{array}$ & N/A \\
\hline Keyword: & liver regeneration, portal vein ligation, microarray, rat model \\
\hline
\end{tabular}


Portal vein ligation alters coding and non-coding gene expression in rat livers

Running title: PVL alters gene expression in rat livers

Bin $\mathrm{Li}^{1}$, Yan $\mathrm{Zhu}^{2}$, Lei Xie ${ }^{1}$, Shuyang $\mathrm{Hu}^{1}$, Shupeng $\mathrm{Liu}^{3}$, Xiaoqing Jiang ${ }^{1}$

1, Biliary Tract Surgery Department I, Eastern Hepatobiliary Surgery Hospital,

Secondary Military Medical University, Shanghai, China

2, Department of Pathology, Changhai Hospital, Secondary Military Medical

University, Shanghai, China

3, Clinical Research Center, Changhai Hospital, Secondary Military Medical

University, Shanghai, China

Corresponding authors: Xiaoqing Jiang, Eastern Hepatobiliary Surgery Hospital, Second Military Medical University, 225 Changhai Road, Shanghai, China; Phone: 86-21-81875281; E-mail: jxqehbh@sina.com; or Shupeng Liu, Changhai Hospital, Second Military Medical University, 168 Changhai Road, Shanghai 200433, China; Phone: 86-21-31162099; E-mail: Ishu_p@aliyun.com.

Conflict of interest: The authors declare they have no conflicts of interest to disclose.

Bin Li and Yan Zhu contributed equally to this article. 


\section{Abstract}

Portal vein occlusion increases the resectability of initially unresectable liver cancer by inducing hypertrophy in non-occluded liver lobes. However, the mechanisms of how portal vein occlusion induces hepatic hypertrophy remain unclear. A cDNA microarray was used to identify the gene expression signatures of ligated (LLLs) and non-ligated lobes (NLLLs) at different time points after portal vein ligation (PVL). The results of a bioinformatics analysis revealed that LLLs and NLLLs displayed different gene expression profiles. Moreover, the expression levels of both coding and non-coding RNA were different between LLLs and NLLLs at different time points after PVL. A Series Test of Cluster analysis revealed that the No. 22 and No. 5 expression patterns, which showed altered expression at $24 \mathrm{~h}$ and maintained this altered expression over the following $14 \mathrm{~d}$, had the lowest $P$ value and the largest number of differentially expressed genes in both LLLs and NLLLs. The results of a GO analysis showed the activation of hypoxia pathways in LLLs and the activation of cell proliferation and cell cycle pathways in NLLLs, suggesting the involvement of these pathways in PVL-induced hepatic hypertrophy and regeneration. These results provide insight into the molecular mechanisms underlying hepatic hypertrophy and regeneration induced by portal vein occlusion, and they identify potential targeting pathways that can promote the clinical application of PVL in liver cancer therapy.

Keywords: portal vein ligation, microarray, rat model, liver regeneration 


\section{Introduction}

Complete hepatic tumor resection is the main option for curative treatment of liver malignancies and provides patients with a chance for long-term survival (Utsunomiya et al. 2014). Up to $70 \%$ of patients are unsuitable for resection because of insufficient remnant liver volume, which always leads to liver failure and increased postoperative morbidity after major liver resection (She and Chok 2015). Portal vein occlusion via embolization (PVE) or ligation (PVL) induces hypertrophy in non-occluded liver lobes and increases the resectability of an inadequate functional remnant liver volume (Siriwardana et al. 2012). It has been reported that PVE is associated with a minimal mortality rate in patients receiving extended hepatectomy (Shindoh et al. 2014). However, the mechanisms of how PVE/PVL induces contralateral hepatic hypertrophy are still poorly understood.

In patients, PVE has been reported to induce apoptosis in the embolized lobe and proliferation in the non-embolized lobe, which may involve the altered expression of transforming growth factor-alpha (TGF- $\alpha$ ) and transforming growth factor-beta (TGF- $\beta$ ) in livers after PVE (Kusaka et al. 2006). Changes in portal flow and cytokine expression after PVE/PVL were also reported in animal models. A reduction in left liver flow and an increase in right liver flow were observed when left portal vein stenosis was performed-results that were further verified by the dilation of the portal branches in the non-embolized lobe (Kawai et al. 2002; Rocheleau et al. 1999). Cytokines and transforming growth 
factors, such as TGF- $\alpha$ and IL6, in both serum and remnant livers were all elevated after PVE/PVL (Garcia-Perez et al. 2015; Kusaka et al. 2004). Hepatic regeneration was promoted by perioperative treatment with HGF, suggesting that the altered genes were involved in liver atrophy and hypertrophy after PVE/PVL (Mangieri et al. 2016). Moreover, the expression of activin beta family members ( $A, C$ and $E$ ) was elevated in the early stage of PVL, indicating the involvement of activin signaling in liver regeneration after PVL (Tashiro 2009). Another study reported that mitochondrial DNA replication and transcription were both enhanced in the non-ligated lobe, which increased the energy supply for liver regeneration (Shimizu et al. 1995). These findings suggest that a complex signal transduction network is activated in livers after PVE/PVL to induce contralateral hepatic hypertrophy and to prevent post-hepatectomy liver failure (Yokoyama et al. 2007). Although many factors have been reported to be involved in PVE/PVL-induced hepatic hypertrophy and liver regeneration, a systematic investigation of the gene expression profiles in livers after PVE/PVL using high-throughput platforms, such as cDNA microarrays, is lacking.

In the present study, we established a rat model of PVL and identified the gene expression signatures of ligated and non-ligated lobes at different times after PVL using cDNA microarrays. We found that PVL induced atrophy in ligated liver lobes (LLLs) and hypertrophy in non-ligated liver lobes (NLLLs) in rats. At different times after PVL (24 h, $7 \mathrm{~d}$ and $14 \mathrm{~d}$ ), both LLLs and NLLLs 
displayed unique gene (coding and non-coding) expression profiles assessed by cluster analysis based on cDNA microarray data. In the first $24 \mathrm{~h}$ after PVL, the expression of most genes was altered. The results of a subsequent GO analysis of these differentially expressed genes showed enrichment of hypoxia, cell proliferation and apoptosis pathways. The present study identified genes involved in PVL and proposes the pathways through which PVL induces hepatic hypertrophy and regeneration. These results may provide further insight into the hepatic hypertrophy and regeneration induced by PVL at the molecular level and potential targeting pathways to promote the clinical application of PVL in liver cancer therapy.

\section{Materials and methods}

\section{Animals}

Male Sprague-Dawley rats, 6-8 weeks old and 140 220 g in weight, were obtained from the Experimental Animal Center of the Second Military Medical University. All rats were maintained in a pathogen-free facility with alternate light and dark conditions and were given standard laboratory rodent chow. All animal experiments (SCXK(HU)2013-0016) were performed in accordance with the institutional guidelines for animal care.

\section{PVL model}

The PVL model was established as previously reported (Dhar et al. 2015). Briefly, abdominal anesthesia was administered using $10 \%$ chloral hydrate at a $0.035 \mathrm{ml} / \mathrm{kg}$ body weight dose. The abdomen was opened via a midline 
incision, and blood vessels including the portal branches and arteries were identified with the help of an operating microscope. The portal vein of the left lobe, the middle lobe and the hepatic papillary was ligated with a double surgical suture to block the blood supply. The PVL model was complete when the color of the right lobe remained light brown, and the other lobes turned dark brown. At 24 h, $3 d, 7 d$ and $14 d$ after PVL, the animals were sacrificed by cervical dislocation. Whole livers were dissected, the total liver weight was measured, and then the individual lobes were weighed separately. Liver tissues were kept in liquid nitrogen for future use.

\section{Microarray analysis}

LLLs and NLLLs were obtained from rats at different time points (24 h, $7 \mathrm{~d}$ and 14 d) after PVL. Normal liver tissues were used as the controls. RNA was isolated from these tissues using TRIzol® Reagent (Invitrogen Life Technologies, Carlsbad, CA) and sent to KANGCHEN Corporation for microarray analysis using the Rat $4 \times 44 \mathrm{~K}$ LncRNA expression array. Data were extracted using Agilent Feature Extraction software. Normalization and further data analysis were performed using Agilent GeneSpring GX v11.5.1 software.

\section{Identification of differentially expressed genes}

The random-variance model (RVM) F-test was applied to identify differentially expressed genes between the normal tissues and LLLs or NLLLs from different time points (24 h, $7 \mathrm{~d}$ and $14 \mathrm{~d})$. After the significance analysis 
and FDR analysis, we selected the differentially expressed genes according to their $\mathrm{P}$ value threshold $(P<0.05)($ Clarke et al. 2008).

\section{Series test of cluster}

A Series Test of Cluster (STC) was used to analyze the dynamic expression of genes in LLLs and NLLLs at different time points, as previously reported (Su et al. 2013).

\section{Gene ontology}

To analyze the differentially expressed genes at the functional level, GO enrichment analyses were performed using the DAVID online tool. $P<0.05$ was considered statistically significant (Liang et al. 2016).

\section{Statistical analyses}

Statistical analyses were performed with SPSS 13.0 for Windows (SPSS). Quantitative variables were analyzed using a t-test. $P<0.05$ was considered statistically significant.

\section{Results}

\section{PVL induced atrophy in LLLs and hypertrophy in NLLLs in rats}

The rat PVL model was established by ligating the portal vein of the left lobe, the middle lobe and hepatic papillary. All the rats survived the procedure and recovered during the postoperative period. At different time points ( $24 \mathrm{~h}, 3$ d, $7 \mathrm{~d}$ and $24 \mathrm{~d}$ ) after the ligation of the portal vein, liver tissues from sacrificed rats $(n=6)$ were weighed. The results showed that the highest whole liver weight (WLW)/body weight (BW) ratio occurred at $7 \mathrm{~d}$ after PVL; no significant 
difference was found at $24 \mathrm{~h}$ or $3 \mathrm{~d}$ (Figure 1A). The NLLL weight (NLLLW)/BW ratio increased along with the time after PVL, whereas the LLL weight (LLLW)/BW ratio decreased (Figure 1B). Similar results were obtained when the NLLLW/WLW and LLLWMLW ratios were analyzed (Figure 1C). These results indicated that PVL induced hypertrophy in NLLLs and atrophy in LLLs in rats.

\section{PVL induced gene expression changes in rat livers}

To investigate gene expression in NLLLs and LLLs at different time points after PVL (0 h, 24 h, $7 \mathrm{~d}$ and $14 \mathrm{~d}$ ), tissues were obtained and sent for cDNA microarray analysis. Multiple genes were found to be differentially expressed in LLLs compared with the corresponding NLLLs at all three time points (Figure $2 A$ and $B$ ). According to the criteria of a fold change $\geq 2.0$ and $P<0.05$, there were 1296, 500 and 530 differentially expressed genes between LLLs and NLLLs at $24 \mathrm{~h}, 7 \mathrm{~d}$ and $14 \mathrm{~d}$, respectively (Figure 2C). Additionally, long non-coding RNAs were analyzed, which revealed that 371, 276 and 165 non-coding RNAs were differentially expressed between LLLs and NLLLs at 24 h, $7 \mathrm{~d}$ and $14 \mathrm{~d}$, respectively (Figure 2D). These results indicated that PVL changed the expression of coding and non-coding genes in both ligated and non-ligated liver lobes.

\section{Gene expression changed over time after PVL}

To investigate gene expression at different times after PVL, we compared changes in the genes expressed in LLLs or NLLLs with those in normal liver. A 
hierarchical clustering analysis showed that both the LLLs and NLLLs had unique mRNA (Figure 3A and B) and non-coding RNA expression profiles at each time point (Figure 3C and D). Additionally, an STC analysis was applied to analyze the dynamic gene expression pattern in relation to the time after PVL. At four different time points, a total of 26 possible dynamic expression profiles were identified. For mRNA, 11 of 26 expression profiles were statistically significant in the LLLs, and 13 profiles were statistically significant in the NLLLs (Figure 4A and B). Among these profiles, 9 profiles were significantly changed in both LLLs and NLLLs. Profiles No. 22 and No. 5 had the lowest $P$ values and the largest number of differentially expressed genes in both groups (Table 1). The expression of genes contained in these two profiles was altered at $24 \mathrm{~h}$, and these expression levels were maintained for the following two weeks. For long non-coding RNAs, 9 profiles in LLLs and 10 profiles in NLLLs were significantly changed (Figure 4C and D). Similar to the mRNA results, 9 profiles were found in both groups, and the two most significant patterns (No. 22 and No. 5) included the largest number of differentially expressed genes (Table 1). In addition, the expression patterns of long non-coding RNAs included in No. 22 and No. 5 were similar to the mRNA data. These results indicated that liver tissues expressed different genes after $\mathrm{PVL}$ and that the largest number of genes was altered during the first $24 \mathrm{~h}$ after PVL.

Hypoxia, cell proliferation and apoptosis pathways enriched by GO 


\section{analysis}

As different gene expression patterns were identified after PVL, we intended to investigate the biological pathways involved in this process. The genes in profiles No. 22 and No. 5 from the STC analysis, which were the most changed profiles, were uploaded to the DAVID online software to identify overrepresented GO categories. The results showed that genes in profile No. 22 from LLLs were significantly enriched in gene transcription, regulation and response to hypoxia for biological processes (BP); DNA and protein binding for molecular function (MF); and the cytoplasm and nucleus for cell components (CC) (Table 2). The genes in profile No. 5 from the LLLs were significantly enriched in BP, including cell cycle and regulation of apoptotic process as well as those presented in profile No. 22 (Table 2). For MF and CC, the enriched categories were same as those found in profile No. 22 (Table 2). The genes in profile No. 22 from the NLLLs were enriched in BP, including regulation of cell proliferation, adhesion, migration and the apoptotic process; MF, including poly(A) RNA binding, ubiquitin-protein transferase activity, cadherin binding involved in cell-cell adhesion and p53 binding; and CC, including cytoplasm, nucleus, nucleoplasm, and Golgi apparatus (Table 3). The genes in profile No. 5 from the NLLLs were enriched in BP, including DNA transcription, protein phosphorylation, cell proliferation and apoptosis; in MF, including protein, ATP, and DNA binding; and in CC, including cytoplasm extracellular exosome and membrane (Table 3). These results indicated that gene transcription and 
protein activity were altered during the first $24 \mathrm{~h}$ after PVL in both LLLs and NLLLs. During this period, the response to hypoxia was apparently activated in LLLs, and proliferation, adhesion and apoptosis of cells were affected in NLLLs.

To gain better insight into the biological processes involved in the response to $\mathrm{PVL}$, the differentially expressed genes at $24 \mathrm{~h}$ between LLLs or NLLLs and the normal control liver were sent for GO BF analysis. A total of 1316 up-regulated and 1578 down-regulated genes were found in LLLs compared with those in the normal control tissues. The results of the GO analysis showed that the up-regulated genes were enriched in hypoxia response and the JNK and ERK signaling pathways (Figure 5A), indicating that PVL induced hypoxia reaction in LLLs. Negative regulation of cell proliferation and positive regulation of epithelial-to-mesenchymal transition (EMT) were also represented in the top rank (Figure 5A), suggesting that cell proliferation was inhibited and that EMT was activated. For down-regulated genes in LLLs, positive transcription regulation, protein phosphorylation and ubiquitin-dependent protein catabolic processes were overrepresented (Figure $5 \mathrm{~B})$, indicating that gene transcription and protein catabolic processes were inhibited in LLLs. For NLLLs, 2151 genes were up-regulated, and 1605 genes were down-regulated. The up-regulated genes were significantly enriched in DNA replication and cell division, and the down-regulated genes were significantly enriched in organic cycling and protein phosphorylation (Figure 5C 
and D), indicating hyperactivation of replication and cell division in NLLLs.

Collectively, these data suggested that PVL induced the hypoxia response and inhibited gene transcription and protein catabolic processes in LLLs and activated DNA replication and cell division in NLLLs.

\section{Discussion}

In the present study, we investigated gene expression in rat liver lobes after PVL using cDNA microarrays. Unique coding and non-coding gene expression profiles were found in both LLLs and NLLLs. Moreover, we found that gene expression in LLLs and NLLLs changed according to the time after PVL. Most of the gene expression changes occurred in the first $24 \mathrm{~h}$ after PVL, and these genes maintained their expression levels for 14 days after PVL. The GO analysis revealed that the genes differentially expressed in the first $24 \mathrm{~h}$ were mostly involved in cell proliferation and the cell cycle.

To the best of our knowledge, few studies have investigated gene expression profiles after PVL in a rat model by high-throughput technologies, such as cDNA microarrays. In the present study, hundreds of aberrantly expressed genes were found in LLLs and NLLLs after PVL, providing evidence that these genes are involved in liver regeneration after PVL. The expression of genes involved in cell division and proliferation in NLLLs was mostly altered by $P V L$, indicating that these were the main biological processes activated in NLLLs and contributed to liver regeneration after PVL. These findings explain why Ki-67 staining increases after PVL/PVE have been reported by others 
(Kusaka et al. 2006; Li et al. 2013). The enrichment of biological processes according to the GO analysis further supports the involvement of cytokines such as TGF- $\beta$ in liver regeneration induced by PVL. TGF- $\beta$ was reported to be related to hypertrophy in the non-embolized liver in patients (Kusaka et al. 2004). According to our data, TGF- $\beta$ was included in the following GO terms: positive regulation of cell proliferation, heart development and positive regulation of cell migration. Additionally, genes involved in the JNK and ERK pathways were aberrantly expressed (Figure 5), supporting previous evidence that angiogenesis and insulin-like growth factor signaling contribute to liver regeneration (Rauchfuss et al. 2012). Moreover, hundreds of non-coding RNAs were aberrantly expressed, suggesting that epigenetic regulation is also involved in liver regeneration.

In agreement with previous reports, we found the highest NLLLW/WLW ratio at $7 \mathrm{~d}$ after PVL in rats (Huisman et al. 2014; Liska et al. 2012). One week can be too long a time interval for some patients and limits the application of PVL in the clinic. We found that multiple pathways, such as positive regulation of cell proliferation and cell cycle, were activated in NLLL, suggesting that the signals involved in these pathways should be used with PVL to improve liver regeneration within a shorter time frame. It has been reported that HGF infusions significantly increased postoperative liver regeneration (Mangieri et al. 2016). Branched-chain amino acid supplementation was also reported to improve functional liver regeneration in patients undergoing PVE (Beppu et al. 
2015). In addition, Schadde et al. reported that hypoxia is likely an accelerator of liver regeneration (Schadde et al. 2017). They found that compared with regenerating liver lobes from rats receiving PVL only or rats sham-operated at 3 and 12 hours, those from rats receiving $\mathrm{PVL}+$ parenchymal transection showed significant hypoxia. In our study, the hypoxia response was activated in LLLs but not in NLLLs at $24 \mathrm{~h}$ after PVL. The parenchymal transection and short time lapse in Schadde's study may be the reason why we observed a different hypoxia status. Collectively, these findings suggest that modification of PVL to accelerate liver regeneration may be more efficient in clinical application.

Although we reported unique gene expression signatures of LLLs and NLLLs after PVL, no functional assays were performed to verify the function of the specific coding and non-coding genes in atrophy or hypotrophy of liver lobes after PVL. In addition, several pathways involved in protein modification and lipid metabolism were also enriched in NLLLs, indicating that regulation at the translational level also contributed to the biological response to PVL. A more thorough elucidation could be obtained if the present results are combined with the results of a proteomic analysis. Moreover, the functions of genes showing different expression profiles (No. 22 and No. 5) remain unclear and require further investigation.

Collectively, unique gene expression signatures were identified in LLLs and NLLLs after PVL in rat model using cDNA microarrays. The results of 
further analysis showed that both coding and non-coding genes were differentially expressed in LLLs and NLLLs after PVL and that the expression levels changed over time. In addition, gene expression patterns assessed by STC showed that the largest number of genes was altered during the first $24 \mathrm{~h}$ at all three time points and that these expression levels were maintained for the following two weeks. The GO analysis showed that pathways involved in hypoxia, cell cycle and cell proliferation were activated in the liver lobes after PVL. Our findings provide a systemic view of the molecular alterations in liver lobes after PVL and provide insight into the mechanism underlying PVL-induced atrophy and hypertrophy.

\section{Acknowledgments}

This work was supported by grants from the Science and Technology Committee of Shanghai Municipality (Nos. 14140902100 and 16140900703) and the National Natural Science Foundation of China (No. 81672899). 


\section{References}

Beppu, T., Nitta, H., Hayashi, H., Imai, K., Okabe, H., Nakagawa, S., Hashimoto, D., Chikamoto, A., Ishiko, T., Yoshida, M., Yamashita, Y., and Baba, H. 2015. Effect of branched-chain amino acid supplementation on functional liver regeneration in patients undergoing portal vein embolization and sequential hepatectomy: a randomized controlled trial. Journal of gastroenterology 50(12): 1197-1205. doi: 10.1007/s00535-015-1067-y.

Clarke, R., Ressom, H.W., Wang, A., Xuan, J., Liu, M.C., Gehan, E.A., and Wang, Y. 2008. The properties of high-dimensional data spaces: implications for exploring gene and protein expression data. Nature reviews 8(1): 37-49.

Dhar, D.K., Mohammad, G.H., Vyas, S., Broering, D.C., and Malago, M. 2015. A novel rat model of liver regeneration: possible role of cytokine induced neutrophil chemoattractant-1 in augmented liver regeneration. Annals of surgical innovation and research 9: 11. doi: 10.1186/s13022-015-0020-3.

Garcia-Perez, R., Revilla-Nuin, B., Martinez, C.M., Bernabe-Garcia, A., Baroja Mazo, A., and Parrilla Paricio, P. 2015. Associated Liver Partition and Portal Vein Ligation (ALPPS) vs Selective Portal Vein Ligation (PVL) for Staged Hepatectomy in a Rat Model. Similar Regenerative Response? PloS one 10(12): e0144096. doi: 10.1371/journal.pone.0144096.

Huisman, F., van Lienden, K.P., Damude, S., Hoekstra, L.T., and van Gulik, T.M. 2014. A review of animal models for portal vein embolization. The Journal of surgical research 191(1): 179-188. doi: 10.1016/j.jss.2014.05.089.

Kawai, M., Naruse, K., Komatsu, S., Kobayashi, S., Nagino, M., Nimura, Y., and Sokabe, M. 2002. Mechanical stress-dependent secretion of interleukin 6 by endothelial cells after portal vein embolization: clinical and experimental studies. Journal of hepatology 37(2): 240-246. 
Kusaka, K., Imamura, H., Tomiya, T., and Makuuchi, M. 2004. Factors affecting liver regeneration after right portal vein embolization. Hepato-gastroenterology 51(56): 532-535.

Kusaka, K., Imamura, H., Tomiya, T., Takayama, T., and Makuuchi, M. 2006. Expression of transforming growth factor-alpha and -beta in hepatic lobes after hemihepatic portal vein embolization. Digestive diseases and sciences 51(8): 1404-1412. doi: 10.1007/s10620-006-9105-5.

Li, T., Zhu, J., Ma, K., Liu, N., Feng, K., Li, X., Wang, S., and Bie, P. 2013. Autologous bone marrow-derived mesenchymal stem cell transplantation promotes liver regeneration after portal vein embolization in cirrhotic rats. The Journal of surgical research 184(2): 1161-1173. doi: 10.1016/j.jss.2013.04.054.

Liang, B., Li, C., and Zhao, J. 2016. Identification of key pathways and genes in colorectal cancer using bioinformatics analysis. Medical oncology 33(10): 111. doi: 10.1007/s12032-016-0829-6.

Liska, V., Treska, V., Mirka, H., Kobr, J., Sykora, R., Skalicky, T., Sutnar, A., Bruha, J., Fiala, O., Vycital, O., Chlumska, A., Holubec, L., Kormunda, S., Trefil, L., Racek, J., and Matejovic, M. 2012. Tumour necrosis factor-alpha stimulates liver regeneration in porcine model of partial portal vein ligation. Hepato-gastroenterology 59(114): 496-500. doi: 10.5754/hge10265.

Mangieri, C.W., McCartt, J.C., Strode, M.A., Lowry, J.E., and Balakrishna, P.M. 2016. Perioperative hepatocyte growth factor (HGF) infusions improve hepatic regeneration following portal branch ligation (PBL) in rodents. Surgical endoscopy. doi: 10.1007/s00464-016-5288-9.

Rauchfuss, F., Lambeck, S., Claus, R.A., Ullmann, J., Schulz, T., Weber, M., Katenkamp, K., Guthke, R., Bauer, M., and Settmacher, U. 2012. Sustained liver regeneration after portal vein embolization --a human molecular pilot study. Digestive and liver disease : official journal of the Italian Society of Gastroenterology and the Italian Association for the Study of the Liver 44(8): 681-688. doi: 
10.1016/j.dld.2012.04.002.

Rocheleau, B., Ethier, C., Houle, R., Huet, P.M., and Bilodeau, M. 1999. Hepatic artery buffer response following left portal vein ligation: its role in liver tissue homeostasis. The American journal of physiology 277(5 Pt 1): G1000-1007.

Schadde, E., Tsatsaris, C., Swiderska-Syn, M., Breitenstein, S., Urner, M., Schimmer, R., Booy, C., Z'Graggen B, R., Wenger, R.H., Spahn, D.R., Hertl, M., Knechtle, S., Diehl, A.M., Schlapfer, M., and Beck-Schimmer, B. 2017. Hypoxia of the growing liver accelerates regeneration. Surgery 161(3): 666-679. doi: 10.1016/j.surg.2016.05.018.

She, W.H., and Chok, K. 2015. Strategies to increase the resectability of hepatocellular carcinoma. World journal of hepatology 7(18): 2147-2154. doi: 10.4254/wjh.v7.i18.2147.

Shimizu, Y., Suzuki, H., Nimura, Y., Onoue, S., Nagino, M., Tanaka, M., and Ozawa, T. 1995. Elevated mitochondrial gene expression during rat liver regeneration after portal vein ligation. Hepatology 22(4 Pt 1): 1222-1229.

Shindoh, J., Tzeng, C.W., Aloia, T.A., Curley, S.A., Huang, S.Y., Mahvash, A., Gupta, S., Wallace, M.J., and Vauthey, J.N. 2014. Safety and efficacy of portal vein embolization before planned major or extended hepatectomy: an institutional experience of 358 patients. Journal of gastrointestinal surgery : official journal of the Society for Surgery of the Alimentary Tract 18(1): 45-51. doi: 10.1007/s11605-013-2369-0.

Siriwardana, R.C., Lo, C.M., Chan, S.C., and Fan, S.T. 2012. Role of portal vein embolization in hepatocellular carcinoma management and its effect on recurrence: a case-control study. World journal of surgery 36(7): 1640-1646. doi: 10.1007/s00268-012-1522-3.

Su, X., Qian, C., Zhang, Q., Hou, J., Gu, Y., Han, Y., Chen, Y., Jiang, M., and Cao, X. 2013. miRNomes of 
haematopoietic stem cells and dendritic cells identify miR-30b as a regulator of Notch1. Nature communications 4: 2903 . doi: $10.1038 /$ ncomms3903.

Tashiro, S. 2009. Mechanism of liver regeneration after liver resection and portal vein embolization (ligation) is different? Journal of hepato-biliary-pancreatic surgery 16(3): 292-299. doi: $10.1007 / \mathrm{s} 00534-009-0058-x$.

Utsunomiya, T., Shimada, M., Kudo, M., Ichida, T., Matsui, O., Izumi, N., Matsuyama, Y., Sakamoto, M., Nakashima, O., Ku, Y., Kokudo, N., Makuuchi, M., and Liver Cancer Study Group of, J. 2014. Nationwide study of 4741 patients with non-B non-C hepatocellular carcinoma with special reference to the therapeutic impact. Annals of surgery 259(2): 336-345. doi: 10.1097/SLA.0b013e31829291e9.

Yokoyama, Y., Nagino, M., and Nimura, Y. 2007. Mechanisms of hepatic regeneration following portal vein embolization and partial hepatectomy: a review. World journal of surgery 31(2): 367-374. doi: 10.1007/s00268-006-0526-2. 
Figure legends

Figure 1. PVL induced atrophy in ligated liver lobes and hypertrophy in non-ligated liver lobes
A) The whole liver weight (WLW)/ body weight (BW) ratio at different times $(n=6)$ after PVL.
B) The ligated liver lobe weight (LLLW)/BW and non-ligated liver lobes
$(\mathrm{NLLLW}) / \mathrm{BW}$ ratios at different times $(\mathrm{n}=6)$ after $\mathrm{PVL}$.
C) The LLLW/WLW and NLLLW/WLW ratios at different times $(n=6)$ after PVL.
${ }^{* *} P<0.01$

Figure 2. PVL altered gene expression in LLLs and NLLLs at different time points after $P V L$

A) Coding genes differentially expressed between LLLs and NLLLs at the same time points ( $24 \mathrm{~h}, 7 \mathrm{~d}$ and $14 \mathrm{~d}$ ) visualized by volcano plots based on the microarray data.

B) Long non-coding genes differentially expressed between LLLs and NLLLs at the same time points ( $24 \mathrm{~h}, 7 \mathrm{~d}$ and $14 \mathrm{~d}$ ) visualized by volcano plots based on microarray data.

C) Number of coding genes up-regulated or down-regulated between LLLs and NLLLs at the time points $24 \mathrm{~h}, 7 \mathrm{~d}$ and $14 \mathrm{~d}$ after PVL.

D) Number of non-coding genes up-regulated or down-regulated between LLLs and NLLLs at the time points $24 \mathrm{~h}, 7 \mathrm{~d}$ and $14 \mathrm{~d}$ after PVL.

Figure 3. Genes were differentially expressed in LLLs or NLLLs at different times after PVL
A) Cluster analysis of coding gene expression in LLLs at different times (0 h, $24 \mathrm{~h}, 7 \mathrm{~d}$ and $14 \mathrm{~d}$ ) after PVL
B) Cluster analysis of coding gene expression in NLLLs at different times $(0 \mathrm{~h}, 24 \mathrm{~h}, 7 \mathrm{~d}$ and $14 \mathrm{~d})$ after PVL
C) Cluster analysis of non-coding gene expression in LLLs at different times ( 0 h, 24 h, $7 \mathrm{~d}$ and $14 \mathrm{~d}$ ) after PVL
D) Cluster analysis of non-coding gene expression in NLLLs at different times (0 h, 24 h, $7 \mathrm{~d}$ and $14 \mathrm{~d}$ ) after PVL

Figure 4. Dynamic coding and non-coding gene expression patterns in LLLs or NLLLs according to the time after PVL
A) The 11 expression profiles of coding genes that were statistically significant in the LLLs over time (0 h, $24 \mathrm{~h}, 7 \mathrm{~d}$ and $14 \mathrm{~d}$ ).
B) The 13 expression profiles of coding genes that were statistically significant in the NLLLs over time ( $0 \mathrm{~h}, 24 \mathrm{~h}, 7 \mathrm{~d}$ and $14 \mathrm{~d}$ ).


C) The 9 expression profiles of non-coding genes that were statistically significant in the LLLs over time ( $0 \mathrm{~h}, 24 \mathrm{~h}, 7 \mathrm{~d}$ and $14 \mathrm{~d}$ ).

D) The 10 expression profiles of non-coding genes that were statistically significant in the NLLLs over time ( $0 \mathrm{~h}, 24 \mathrm{~h}, 7 \mathrm{~d}$ and $14 \mathrm{~d}$ ).

Figure 5. GO analysis results of differentially expressed genes between LLLs or NLLLs and normal control liver at $\mathbf{2 4 ~ h}$

A) Top-ranking biological pathways enriched in up-regulated genes in LLLs compared to those in normal control livers according to the GO analysis.

B) Top-ranking biological pathways enriched in down-regulated genes in LLLs compared to those in normal control livers according to the GO analysis.

C) Top-ranking biological pathways enriched in up-regulated genes in NLLLs compared to those in normal control livers according to the GO analysis.

D) Top-ranking biological pathways enriched in down-regulated genes in NLLLs compared to those in normal control livers according to the $\mathrm{GO}$ analysis. 

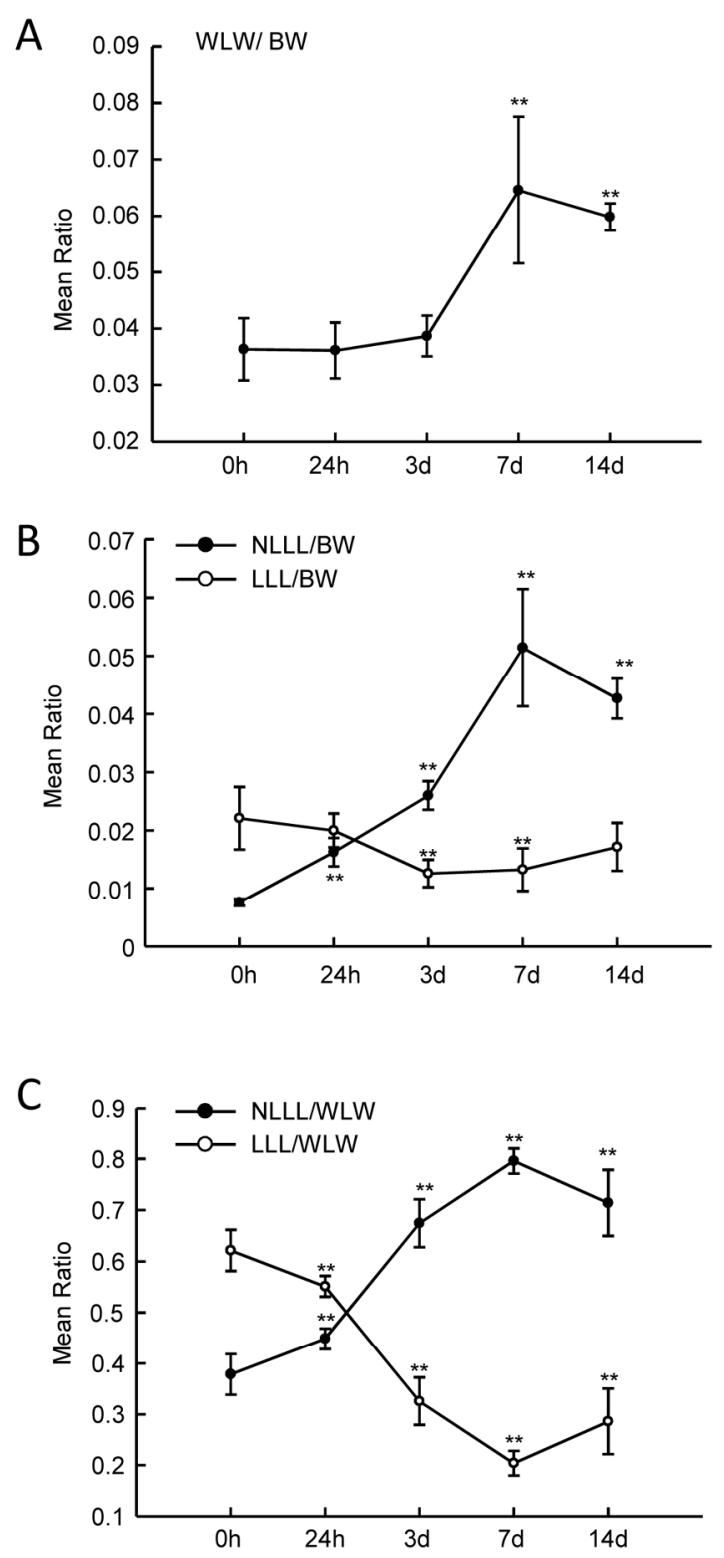

$94 \times 204 \mathrm{~mm}(300 \times 300 \mathrm{DPI})$ 
A
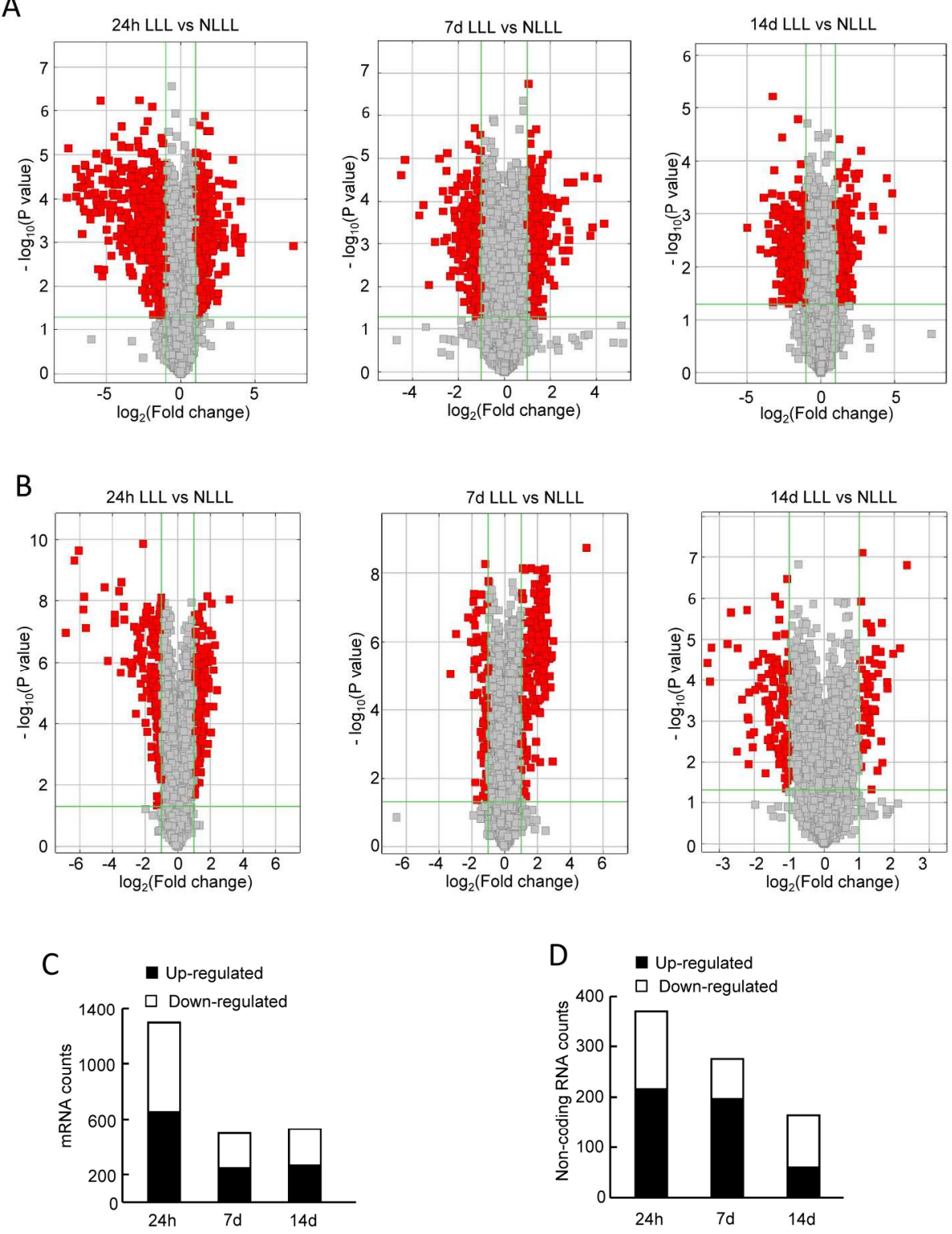

$183 \times 236 \mathrm{~mm}(300 \times 300$ DPI $)$ 

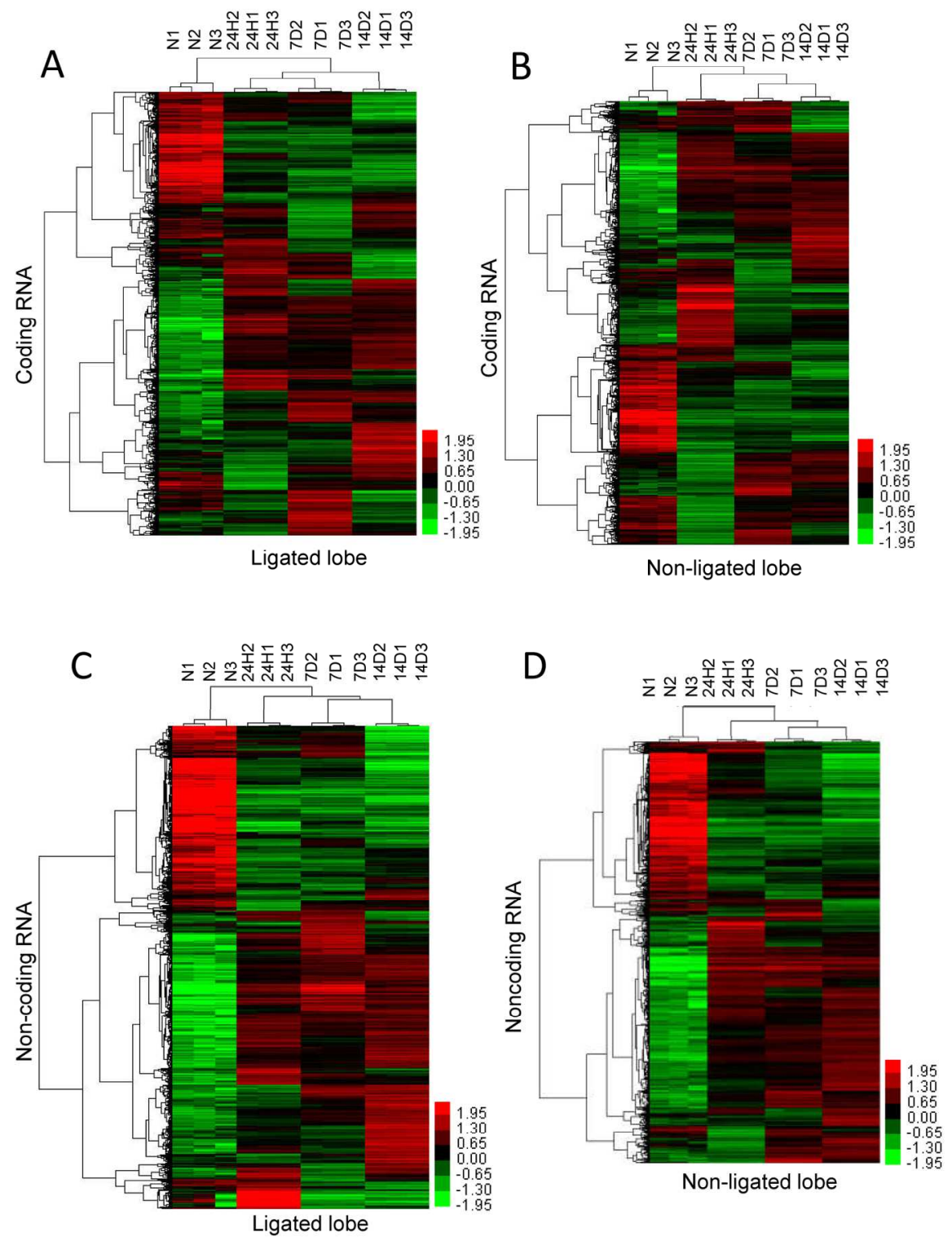

$148 \times 188 \mathrm{~mm}(300 \times 300$ DPI $)$ 


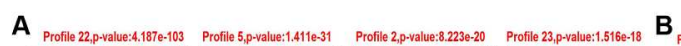

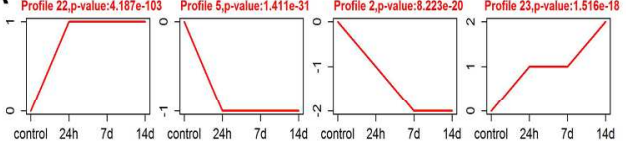

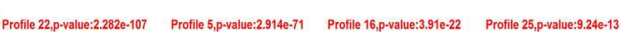


Profile 4,0-value:3.472e-12 Profile 25,p-value:5.0866-12 Profile 1,p-value:1.948-11 Profile 26,p-value:1678 -99
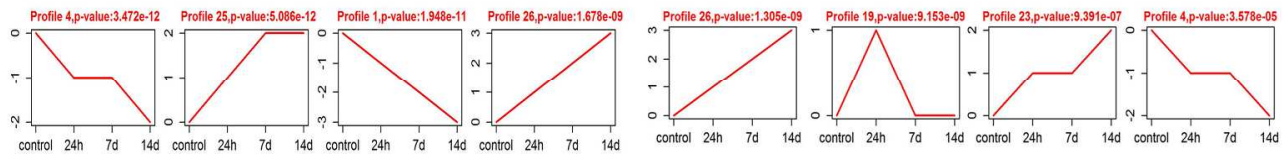

contol $24 \mathrm{~h}$ 7d $14 \mathrm{~d}$ contiol $24 \mathrm{~h}$ 7d $14 \mathrm{~d}$ conitrol $24 \mathrm{~h}$ 7d $14 \mathrm{~d}$ control $24 \mathrm{~h}$ 7d $14 \mathrm{~d}$ Profile 24,p-value:1.727e-06 Profile 21,p-value:0.002545 Profile 17,p-value:0.0102
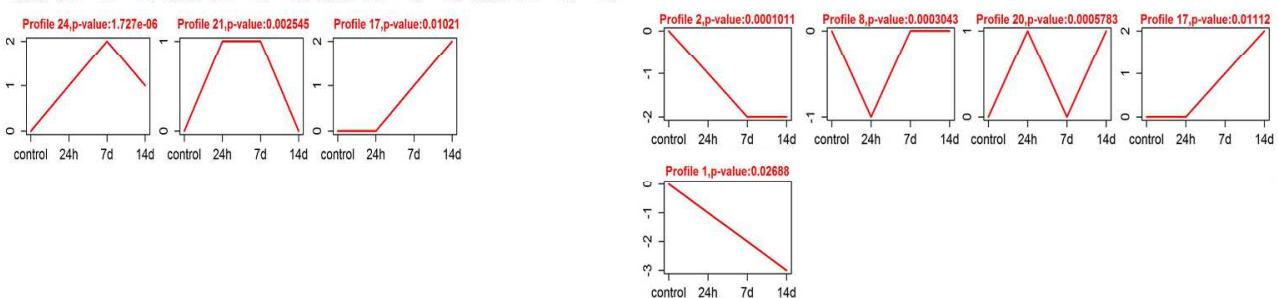

C



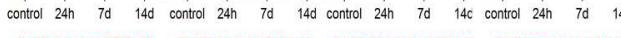
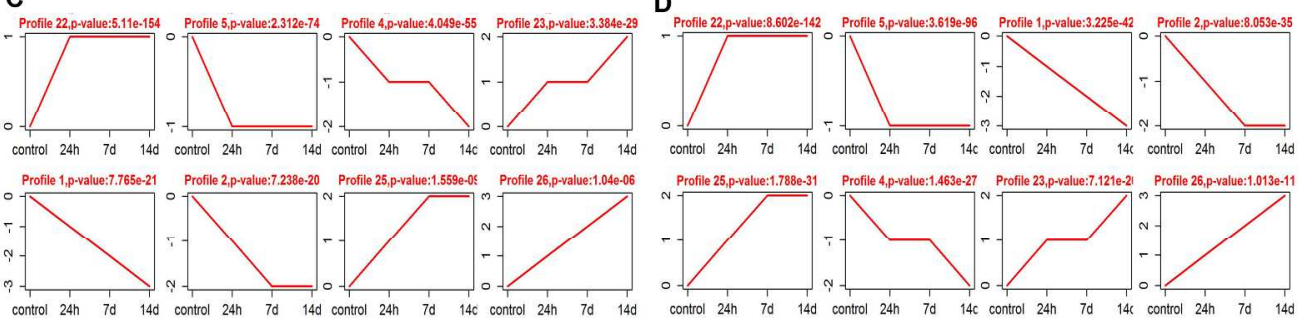
Profile 20.0.value:0.0003982


$209 \times 182 \mathrm{~mm}(300 \times 300 \mathrm{DPI})$ 

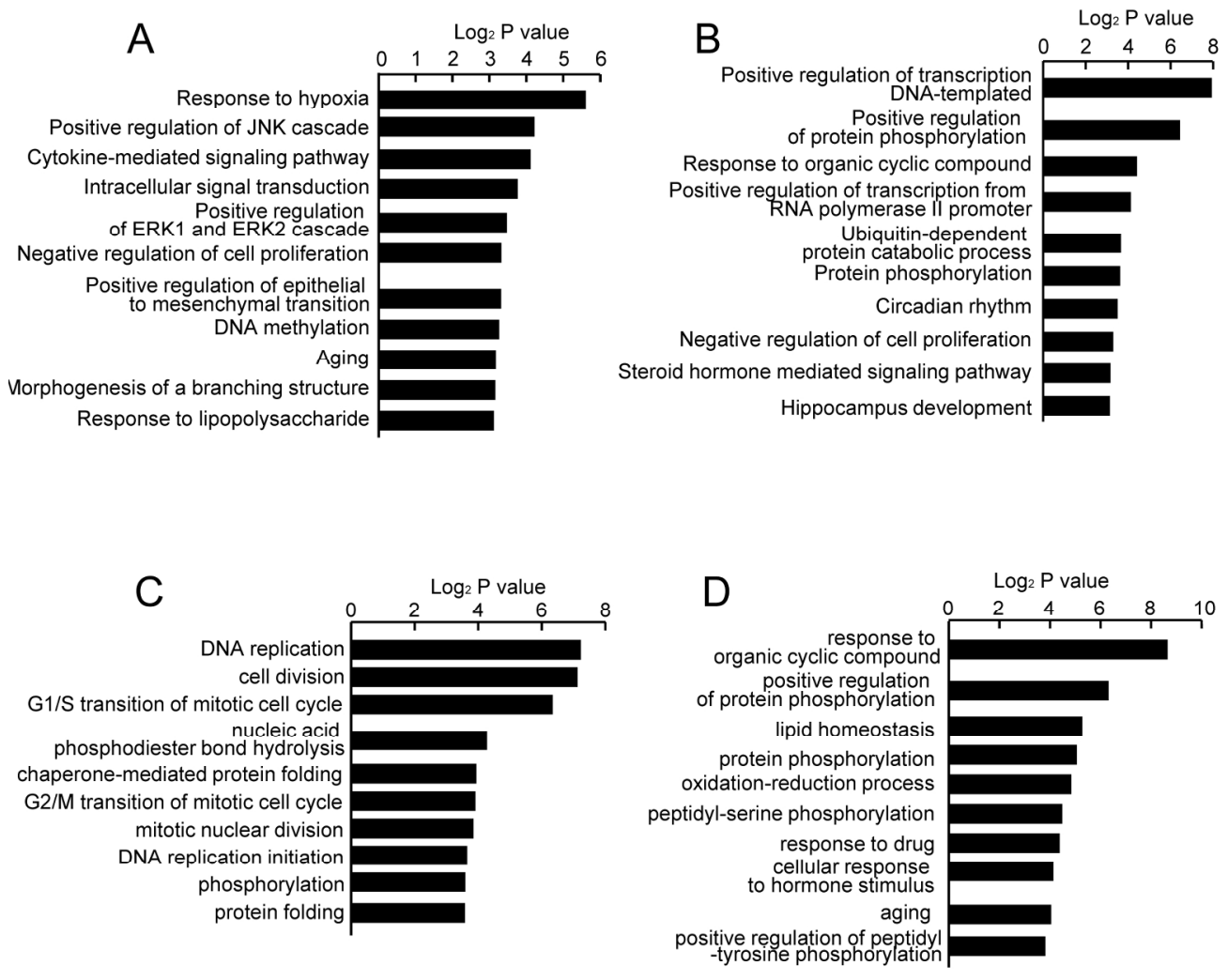

$187 \times 154 \mathrm{~mm}(300 \times 300 \mathrm{DPI})$ 
Table 1. Different Coding and non-coding gene expression patterns along with PVL time in LLL and NLLL

\begin{tabular}{|c|c|c|c|c|c|}
\hline \multicolumn{3}{|c|}{ ligated liver lobes(LLL) } & \multicolumn{3}{|c|}{ non-ligated liver lobes(NLLL) } \\
\hline $\begin{array}{c}\text { Profile } \\
\text { NO. }\end{array}$ & $\begin{array}{l}\text { Genes } \\
\text { Counts }\end{array}$ & $\begin{array}{c}\mathrm{P} \\
\text { value }\end{array}$ & $\begin{array}{c}\text { Profile } \\
\text { NO. }\end{array}$ & $\begin{array}{l}\text { Genes } \\
\text { Counts }\end{array}$ & $\begin{array}{c}\mathrm{P} \\
\text { value }\end{array}$ \\
\hline \multicolumn{6}{|l|}{ coding RNA } \\
\hline Profile22 & 851 & 0 & Profile22 & 875 & 0 \\
\hline Profile5 & 518 & 0 & Profile5 & 688 & 0 \\
\hline Profile2 & 185 & 0 & Profile16 & 253 & 0 \\
\hline Profile23 & 256 & 0 & Profile25 & 168 & 0 \\
\hline Profile4 & 230 & 0 & Profile26 & 87 & 0 \\
\hline Profile25 & 158 & 0 & Profile19 & 540 & 0 \\
\hline Profile1 & 98 & 0 & Profile23 & 187 & 0 \\
\hline Profile26 & 92 & 0 & Profile4 & 177 & 0 \\
\hline Profile24 & 240 & 0 & Profile2 & 115 & 0 \\
\hline Profile21 & 266 & 0 & Profile8 & 569 & 0 \\
\hline \multirow[t]{3}{*}{ Profile17 } & 111 & 0.01 & Profile20 & 294 & 0 \\
\hline & & & Profile17 & 101 & 0.01 \\
\hline & & & Profile1 & 56 & 0.03 \\
\hline \multicolumn{6}{|l|}{ non-coding RNA } \\
\hline Profile22 & 664 & 0 & Profile22 & 648 & 0 \\
\hline Profile5 & 527 & 0 & Profile5 & 525 & 0 \\
\hline Profile4 & 250 & 0 & Profile1 & 105 & 0 \\
\hline Profile23 & 195 & 0 & Profile2 & 138 & 0 \\
\hline Profile1 & 77 & 0 & Profile25 & 141 & 0 \\
\hline Profile2 & 120 & 0 & Profile4 & 169 & 0 \\
\hline Profile25 & 87 & 0 & Profile23 & 150 & 0 \\
\hline Profile26 & 47 & 0 & Profile26 & 56 & 0 \\
\hline Profile20 & 147 & 0 & Profile16 & 77 & 0.01 \\
\hline & & & Profile20 & 127 & 0.04 \\
\hline
\end{tabular}


Table 2. GO analysis of genes in Profile 22 and Profile 5 from ligated liver lobes.

\begin{tabular}{|c|c|c|c|c|}
\hline \multicolumn{5}{|l|}{ Profile 22} \\
\hline Category & Term/gene function & $\begin{array}{l}\text { Gene } \\
\text { Count }\end{array}$ & $\%$ & $\mathrm{P}$ \\
\hline \multirow[t]{7}{*}{ GOTERM_BP_DIRECT } & $\begin{array}{l}\text { GO:0000122 negative regulation of transcription } \\
\text { from RNA polymerase II promoter }\end{array}$ & 38 & 5.9 & 0.01 \\
\hline & $\begin{array}{l}\text { GO:0045892 negative regulation of } \\
\text { transcription, DNA-templated }\end{array}$ & 28 & 4.35 & 0.01 \\
\hline & GO:0006351 transcription, DNA-templated & 37 & 5.75 & 0.02 \\
\hline & $\begin{array}{l}\text { GO:0045944 positive regulation of transcription } \\
\text { from RNA polymerase II promoter }\end{array}$ & 45 & 6.99 & 0.03 \\
\hline & $\begin{array}{l}\text { GO:0006357 regulation of transcription from } \\
\text { RNA polymerase II promoter }\end{array}$ & 23 & 3.57 & 0.03 \\
\hline & GO:0001666 response to hypoxia & 16 & 2.48 & 0.03 \\
\hline & $\begin{array}{l}\text { GO:0006355 regulation of transcription, } \\
\text { DNA-templated }\end{array}$ & 46 & 7.14 & 0.03 \\
\hline \multirow[t]{7}{*}{ GOTERM_MF_DIRECT } & GO:0005515 protein binding & 77 & 11.96 & 0 \\
\hline & GO:0043565 sequence-specific DNA binding & 30 & 4.66 & 0.01 \\
\hline & GO:0003682 chromatin binding & 25 & 3.88 & 0.01 \\
\hline & GO:0003677 DNA binding & 49 & 7.61 & 0.01 \\
\hline & GO:0044822 poly(A) RNA binding & 51 & 7.92 & 0.01 \\
\hline & GO:0008270 zinc ion binding & 48 & 7.45 & 0.01 \\
\hline & GO:0004672 protein kinase activity & 16 & 2.48 & 0.03 \\
\hline \multirow[t]{6}{*}{ GOTERM_CC_DIRECT } & GO:0005737 cytoplasm & 222 & 34.47 & 0 \\
\hline & GO:0005634 nucleus & 204 & 31.68 & 0 \\
\hline & GO:0005794 Golgi apparatus & 39 & 6.06 & 0.02 \\
\hline & GO:0043234 protein complex & 33 & 5.12 & 0 \\
\hline & GO:0048471 perinuclear region of cytoplasm & 33 & 5.12 & 0.01 \\
\hline & GO:0000790 nuclear chromatin & 17 & 2.64 & 0 \\
\hline \multicolumn{5}{|l|}{ Profile 5} \\
\hline Category & Term/gene function & $\begin{array}{l}\text { Gene } \\
\text { Count }\end{array}$ & $\%$ & $\mathrm{P}$ \\
\hline \multirow{5}{*}{ GOTERM_BP_DIRECT } & GO:0007049 cell cycle & 12 & 1.86 & 0 \\
\hline & GO:0016310 phosphorylation & 12 & 1.86 & 0.01 \\
\hline & $\begin{array}{l}\text { GO:0000122 negative regulation of transcription } \\
\text { from RNA polymerase II promoter }\end{array}$ & 38 & 5.9 & 0.01 \\
\hline & GO:0001501 skeletal system development & 10 & 1.55 & 0.01 \\
\hline & $\begin{array}{l}\text { GO:0045892 negative regulation of } \\
\text { transcription, DNA-templated }\end{array}$ & 28 & 4.35 & 0.01 \\
\hline
\end{tabular}




\begin{tabular}{|c|c|c|c|c|}
\hline & GO:0006351 transcription, DNA-templated & 37 & 5.75 & 0.02 \\
\hline & GO:0010033 response to organic substance & 11 & 1.71 & 0.02 \\
\hline & $\begin{array}{l}\text { GO:0045944 positive regulation of transcription } \\
\text { from RNA polymerase II promoter }\end{array}$ & 45 & 6.99 & 0.03 \\
\hline & $\begin{array}{l}\text { GO:0006357 regulation of transcription from } \\
\text { RNA polymerase II promoter }\end{array}$ & 23 & 3.57 & 0.03 \\
\hline & GO:0001666 response to hypoxia & 16 & 2.48 & 0.03 \\
\hline & $\begin{array}{l}\text { GO:0006355 regulation of transcription, } \\
\text { DNA-templated }\end{array}$ & 46 & 7.14 & 0.03 \\
\hline & GO:0098609 cell-cell adhesion & 13 & 2.02 & 0.04 \\
\hline & GO:0010468 regulation of gene expression & 14 & 2.17 & 0.04 \\
\hline & GO:0042981 regulation of apoptotic process & 11 & 1.71 & 0.05 \\
\hline GOTFRM MF $\mathrm{OIRECT}$ & GO:0005515 protein binding & 77 & 11.96 & 0 \\
\hline GUILNIVI_ & GO:0043565 sequence-specific DNA binding & 30 & 4.66 & 0.01 \\
\hline & GO:0003682 chromatin binding & 25 & 3.88 & 0.01 \\
\hline & GO:0003677 DNA binding & 49 & 7.61 & 0.01 \\
\hline & GO:0044822 poly(A) RNA binding & 51 & 7.92 & 0.01 \\
\hline & GO:0008270 zinc ion binding & 48 & 7.45 & 0.01 \\
\hline & $\begin{array}{l}\text { GO:0003700 transcription factor activity, } \\
\text { sequence-specific DNA binding }\end{array}$ & 35 & 5.43 & 0.03 \\
\hline & GO:0004672 protein kinase activity & 16 & 2.48 & 0.03 \\
\hline GOTFRM & GO:0005737 cytoplasm & 222 & 34.47 & 0 \\
\hline GUIERIVICC_UIRECI & GO:0005634 nucleus & 204 & 31.68 & 0 \\
\hline & GO:0000790 nuclear chromatin & 17 & 2.64 & 0 \\
\hline & GO:0005654 nucleoplasm & 78 & 12.11 & 0 \\
\hline & GO:0005730 nucleolus & 42 & 6.52 & 0 \\
\hline & GO:0043234 protein complex & 33 & 5.12 & 0 \\
\hline & GO:0048471 perinuclear region of cytoplasm & 33 & 5.12 & 0.01 \\
\hline & GO:0005794 Golgi apparatus & 39 & 6.06 & 0.02 \\
\hline
\end{tabular}


Table 3. GO analysis of genes in Profile 22 and Profile 5 from non-ligated liver lobes.

\begin{tabular}{|c|c|c|c|c|}
\hline \multicolumn{5}{|l|}{ Profile 22} \\
\hline Category & Term & Count & $\%$ & $P$ \\
\hline \multirow[t]{9}{*}{ GOTERM_BP_DIRECT } & GO:0008284 positive regulation of cell & 27 & 0.03 & 0.02 \\
\hline & proliferation & & & \\
\hline & GO:0007507 heart development & 18 & 0.02 & 0.02 \\
\hline & GO:0030335 positive regulation of cell migration & 16 & 0.02 & 0 \\
\hline & GO:0098609 cell-cell adhesion & 14 & 0.01 & 0.03 \\
\hline & GO:0007049 cell cycle & 13 & 0.01 & 0 \\
\hline & GO:0007605 sensory perception of sound & 13 & 0.01 & 0 \\
\hline & GO:0042981 regulation of apoptotic process & 13 & 0.01 & 0.01 \\
\hline & GO:0016192 vesicle-mediated transport & 11 & 0.01 & 0.01 \\
\hline \multirow[t]{15}{*}{ GOTERM_MF_DIRECT } & GO:0005515 protein binding & 79 & 11.92 & 0 \\
\hline & GO:0044822 poly(A) RNA binding & 60 & 9.05 & 0 \\
\hline & GO:0046982 protein heterodimerization activity & 28 & 4.22 & 0.03 \\
\hline & GO:0032403 protein complex binding & 24 & 3.62 & 0 \\
\hline & GO:0003723 RNA binding & 24 & 3.62 & 0.04 \\
\hline & GO:0004842 ubiquitin-protein transferase activity & 19 & 2.87 & 0.02 \\
\hline & GO:0019904 protein domain specific binding & 18 & 2.71 & 0.03 \\
\hline & GO:0008022 protein C-terminus binding & 14 & 2.11 & 0.02 \\
\hline & $\begin{array}{l}\text { GO:0098641 cadherin binding involved in cell-cell } \\
\text { adhesion }\end{array}$ & 14 & 2.11 & 0.03 \\
\hline & GO:0005179 hormone activity & 12 & 1.81 & 0 \\
\hline & GO:0005516 calmodulin binding & 11 & 1.66 & 0.04 \\
\hline & GO:0044325 ion channel binding & 10 & 1.51 & 0.03 \\
\hline & GO:0019903 protein phosphatase binding & 8 & 1.21 & 0.03 \\
\hline & GO:0002039 p53 binding & 7 & 1.06 & 0.03 \\
\hline & $\begin{array}{l}\text { GO:0000980 RNA polymerase II distal enhancer } \\
\text { sequence-specific DNA binding }\end{array}$ & 7 & 1.06 & 0.03 \\
\hline \multirow{9}{*}{ GOTERM_CC_DIRECT } & GO:0005737 cytoplasm & 209 & 0.21 & 0 \\
\hline & GO:0005634 nucleus & 198 & 0.19 & 0 \\
\hline & GO:0005654 nucleoplasm & 76 & 0.07 & 0.01 \\
\hline & GO:0005794 Golgi apparatus & 49 & 0.05 & 0 \\
\hline & GO:0005730 nucleolus & 47 & 0.05 & 0 \\
\hline & GO:0005622 intracellular & 47 & 0.05 & 0.02 \\
\hline & $\begin{array}{l}\text { GO:0005887 integral component of plasma } \\
\text { membrane }\end{array}$ & 43 & 0.04 & 0.03 \\
\hline & GO:0043234 protein complex & 38 & 0.04 & 0 \\
\hline & GO:0048471 perinuclear region of cytoplasm & 38 & 0.04 & 0 \\
\hline
\end{tabular}




\begin{tabular}{|c|c|c|c|c|}
\hline & GO:0005783 endoplasmic reticulum & 38 & 0.04 & 0.03 \\
\hline \multicolumn{5}{|l|}{ Profile 5} \\
\hline Category & Term & Count & $\%$ & $\mathrm{P}$ \\
\hline \multirow[t]{23}{*}{ GOTERM_BP_DIRECT } & $\begin{array}{l}\text { GO:0045944 positive regulation of transcription } \\
\text { from RNA polymerase II promoter }\end{array}$ & 49 & 9.18 & 0 \\
\hline & $\begin{array}{l}\text { GO:0006355 regulation of transcription, } \\
\text { DNA-templated }\end{array}$ & 43 & 8.05 & 0.01 \\
\hline & $\begin{array}{l}\text { GO:0045893 positive regulation of transcription, } \\
\text { DNA-templated }\end{array}$ & 36 & 6.74 & 0 \\
\hline & GO:0006351 transcription, DNA-templated & 34 & 6.37 & 0.01 \\
\hline & $\begin{array}{l}\text { GO:0000122 negative regulation of transcription } \\
\text { from RNA polymerase II promoter }\end{array}$ & 33 & 6.18 & 0.01 \\
\hline & GO:0006468 protein phosphorylation & 27 & 5.06 & 0 \\
\hline & $\begin{array}{l}\text { GO:0045892 negative regulation of transcription, } \\
\text { DNA-templated }\end{array}$ & 27 & 5.06 & 0 \\
\hline & GO:0007165 signal transduction & 27 & 5.06 & 0.02 \\
\hline & GO:0055114 oxidation-reduction process & 27 & 5.06 & 0.03 \\
\hline & $\begin{array}{l}\text { GO:0043066 negative regulation of apoptotic } \\
\text { process }\end{array}$ & 24 & 4.49 & 0.01 \\
\hline & $\begin{array}{l}\text { GO:0008285 negative regulation of cell } \\
\text { proliferation }\end{array}$ & 23 & 4.31 & 0 \\
\hline & $\begin{array}{l}\text { GO:0014070 response to organic cyclic } \\
\text { compound }\end{array}$ & 16 & 3 & 0.01 \\
\hline & GO:0007623 circadian rhythm & 15 & 2.81 & 0 \\
\hline & GO:0055085 transmembrane transport & 15 & 2.81 & 0 \\
\hline & GO:0001701 in utero embryonic development & 15 & 2.81 & 0.02 \\
\hline & GO:0010468 regulation of gene expression & 14 & 2.62 & 0.01 \\
\hline & $\begin{array}{l}\text { GO:0001934 positive regulation of protein } \\
\text { phosphorylation }\end{array}$ & 13 & 2.43 & 0 \\
\hline & GO:0030335 positive regulation of cell migration & 12 & 2.25 & 0.02 \\
\hline & GO:0030182 neuron differentiation & 11 & 2.06 & 0.01 \\
\hline & GO:0046777 protein autophosphorylation & 11 & 2.06 & 0.03 \\
\hline & GO:0030324 lung development & 10 & 1.87 & 0.01 \\
\hline & $\begin{array}{l}\text { GO:0043524 negative regulation of neuron } \\
\text { apoptotic process }\end{array}$ & 10 & 1.87 & 0.03 \\
\hline & $\begin{array}{l}\text { GO:0048146 positive regulation of fibroblast } \\
\text { proliferation }\end{array}$ & 9 & 1.69 & 0 \\
\hline \multirow{6}{*}{ GOTERM_MF_DIRECT } & GO:0005515 protein binding & 70 & 13.11 & 0 \\
\hline & GO:0005524 ATP binding & 52 & 9.74 & 0.02 \\
\hline & GO:0008270 zinc ion binding & 47 & 8.8 & 0 \\
\hline & GO:0003677 DNA binding & 46 & 8.61 & 0 \\
\hline & $\begin{array}{l}\text { GO:0003700 transcription factor activity, } \\
\text { sequence-specific DNA binding }\end{array}$ & 35 & 6.55 & 0 \\
\hline & GO:0042803 protein homodimerization activity & 33 & 6.18 & 0.02 \\
\hline
\end{tabular}




\begin{tabular}{lllll} 
& GO:0043565 sequence-specific DNA binding & 32 & 5.99 & 0 \\
& GO:0046982 protein heterodimerization activity & 25 & 4.68 & 0.02 \\
& GO:0032403 protein complex binding & 24 & 4.49 & 0 \\
& GO:0003682 chromatin binding & 23 & 4.31 & 0.01 \\
\hline \multirow{2}{*}{ GOTERM_CC_DIRECT } & GO:0005737 cytoplasm & 163 & 30.52 & 0.01 \\
& GO:0070062 extracellular exosome & 99 & 18.54 & 0 \\
& GO:0016020 membrane & 85 & 15.92 & 0 \\
GO:0005829 cytosol & 70 & 13.11 & 0 \\
GO:0043234 protein complex & 31 & 5.81 & 0 \\
GO:0048471 perinuclear region of cytoplasm & 31 & 5.81 & 0 \\
GO:0043025 neuronal cell body & 29 & 5.43 & 0 \\
GO:0009986 cell surface & 28 & 5.24 & 0.01 \\
GO:0043231 intracellular membrane-bounded & 28 & 5.24 & 0.03 \\
organelle & 22 & 4.12 & 0 \\
\hline
\end{tabular}

